
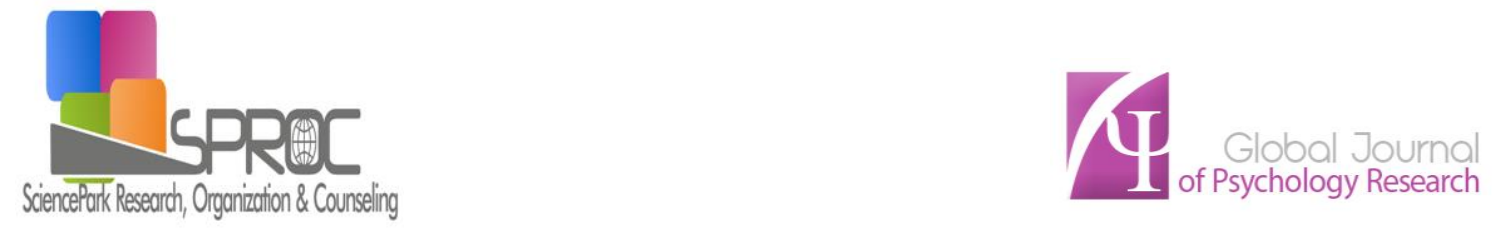

http://sproc.org/ojs/index.php/gipr

\title{
Fractal images - a new way to reduce stress and to improve educational workspaces
}

Maria Raluca Simion *,

Suggested Citation:

Global Journal of Psychology Research. 6

Abstract 
Global Journal of

Psychology Research. 6

\section{Background}


Global Journal of

Psychology Research. 6

2. Purpose of the study 
Psychology Research. 6

Global Journal of

3. Sources of evidence 
Psychology Research. 6

Global Journal of 
Global Journal of

Psychology Research. 6

4. Main argument 
Psychology Research. 6

Global Journal of 
Global Journal of

Psychology Research. 6

\section{Conclusion}


Global Journal of

Psychology Research. 6

\section{Acknowledgements}

$\boldsymbol{R}$

R 


\section{References}

Psychological Science, 19

Astrophysical Journal Letters, 488

Journal Neural Computatio, 14

Applied Ergonomics 18

Parenting

Handbook of Parenting: Practical Issues in

Explore 8 
Global Journal of

Psychology Research. 6

J Pediatr Nurs 24

and Social Psychology Bulletin 35

Wilson, Edward O. (1984). Biophilia. Cambridge:

Proceedings of the 46th Meeting of The Human Factors and Ergonomics Society 